\title{
Development of a heavy metal-inducible fish- specific expression vector for gene transfer in vitro and in vivo*
}

\author{
Yunhan Hong ${ }^{\mathrm{a}, 1}$, Christoph Winkler ${ }^{\mathrm{a}, 1}$, Gottfried Brem $^{\mathrm{b}}$ and Manfred Schartl ${ }^{\mathrm{a}, 1}$ \\ ${ }^{a}$ Genzentrum, Max-Planck-Institut für Biochemie, Martinsried, Germany \\ 'Institut für Tierzucht und Tierhygiene der Ludwig-Maximilians-Universität München. Germany
}

\begin{abstract}
Hong, Y., Winkler, C., Brem, G. and Schartl, M., 1993. Development of a heavy metal-inducible fishspecific expression vector for gene transfer in vitro and in vivo. Aquaculture, 111:215-226.

The promoter of the rainbow trout metallothionein B gene (tMTb) was isolated from genomic DNA by the polymerase chain reaction (PCR), fused to the bacterial chloramphenicol acetyltransferase (CAT) gene in an expression vector, and functionally analyzed in one human cell line and four fish cell lines. This promoter exhibited an extremely low basal expression in all cell lines and was zincand cadmium-inducible except in the fish melanoma cell line where the promoter was completely inactive. The metal-induced expression patterns were cell line-specific. In general the fish promoter was more species- and cell type-specific than its human counterpart. In a transient assay it was functional in developing embryos of the medaka (Oryzias latipes). These properties make this promoter suitable for inducible, tissue-specific expression of transgenes and for in vivo studies of gene function and regulation.
\end{abstract}

\section{INTRODUCTION}

Transgenic fish are of interest for basic biological studies and for genetic improvement of aquaculture species. The report of Palmiter et al. (1982) that transgenic mice containing the rat growth hormone $(\mathrm{rGH})$ gene fused to the mouse metallothionein (mMT) promoter grew much faster than their siblings has encouraged the investigation on the production of transgenic livestock including fish. Zhu et al. (1985) microinjected the mMT-hGH (human GH gene) into the fertilized eggs of goldfish (Carassius auratus) and de-

Correspondence to: Dr. Manfred Schartl, Biocenter, Physiological Chemistry I, University of Würzburg, Am Hubland, 8700 Würzburg, Germany.

'Present address: Biocenter, Physiological Chemistry I, University of Würzburg, Am Hubland, 8700 Würzburg, Germany.

*Contains part of the Ph.D. thesis of Y.H. 
tected integration of the injected DNA. Since then transgenic fish have been attempted in more than ten species using heterologous promoters (for review see Chen and Powers, 1990). In most cases, however, the foreign genes were not effectively expressed. This might, at least partly, be due to the heterologous origins of the promoters used. For further approaches it may be advantageous to use fish promoters both for effective expression of transgenes and for marketability of transgenic aquaculture products.

Few reports are available concerning investigation of fish promoters (Zafarullah et al., 1988; Friedenreich and Schartl, 1990; Liu et al., 1990). In rainbow trout there are two isoforms of metallothionein (MT) genes, A and B (Bonham et al., 1987). Although the promoter of the B gene has been reported to be able to drive expression of a reporter gene in cell cultures, little is known about its specifity in fish cells as well as its functionality in vivo in developing fish embryos. In order to construct fish-specific expression vectors for studies on gene regulation in vitro and/or in vivo and for the production of transgenic fish, we have isolated the promoter region of the rainbow trout metallothionein B gene (tMTb) using the polymerase chain reaction and tested its functionality and expression patterns in one human cell line and four fish cell lines as well as in developing embryos of Japanese medaka (Oryzias latipes).

\section{MATERIAL AND METHODS}

\section{PCR amplification of the promoter sequence}

Genomic DNA was prepared from blood cells of rainbow trout (Oncorhynchus mykiss). Two oligonucleotide primers, BL2 and BR2, were synthesized on a DNA synthesizer (Applied Biosystem Inc.) and purified by PAGE (Sambrook et al., 1989). BL2 (5'-tcgaattCTGATTAAGTTTTGTATAGTTAAATAAAT $-3^{\prime}$ ) contains the $5^{\prime}$ end of the published sequence (from -250 to -221) of the rainbow trout MT-B gene (Zafarullah et al., 1988); BR2 (5'ttgaattcCTTTTAGAGCATTCACAAGGATCCAT-3') is complementary to the first exon of the same gene (Fig. 3). Both primers contain an EcoRI site at their $5^{\prime}$ ends (small letters) for further cloning.

Polymerase chain reactions (PCR) were performed on a self-built PCR machine (Wittbrodt and Erhardt, 1989). Each reaction in a total volume of $50 \mu \mathrm{l}$ contained $1 \times \mathrm{PCR}$ buffer, $50 \mathrm{p} M$ of each primer, $100 \mu M$ of each of dATP, dTTP, dGTP and dCTP (Pharmacia), 50-200 ng of trout genomic DNA, and 1-2.5 units of Taq DNA polymerase (Amersham). Two buffers were used. AM buffer consists of $67 \mathrm{mM}$ Tris-Cl, $\mathrm{pH} 8.8,6.7 \mathrm{mM} \mathrm{MgSO}_{4}$, $16.6 \mathrm{mM}\left(\mathrm{NH}_{4}\right)_{2} \mathrm{SO}_{4}, 10 \mathrm{~m} M \beta$-mercaptoethanol; Cetus buffer contains 10 $\mathrm{m} M$ Tris-Cl, $\mathrm{pH} 8.3,1.5 \mathrm{~m} M \mathrm{MgCl}_{2}, 5 \mathrm{mM} \mathrm{KCl}$ and $0.1 \mathrm{mg} / \mathrm{ml}$ gelatin. The samples were denatured for $5 \mathrm{~min}$ at $92^{\circ} \mathrm{C}$, followed by 35 reaction cycles ( 1 


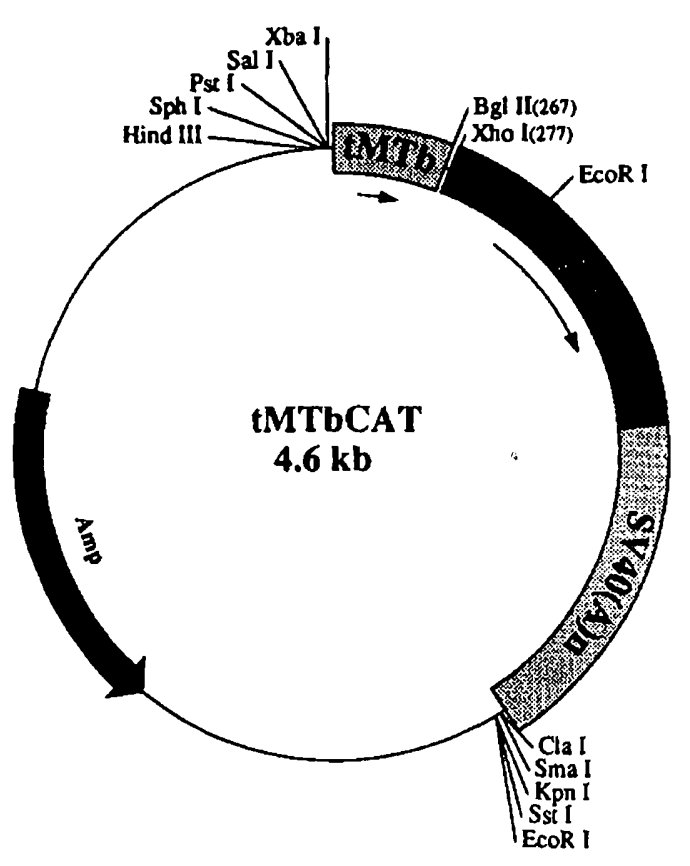

Fig. 1. Structure of expression vector ptMTb-CAT. Plasmid ptMTb-CAT (4.6 kb) consists of the 261bp fragment of the rainbow trout metallothionein B gene promoter (tMTb), the 1.6-kb fragment containing the bacterial chloramphenicol acetyltransferase gene (CAT) and the SV40 polyadenylation signal sequence [SV40(A)n], and the $2.7 \mathrm{~kb}$ fragment of pUC18.

min denaturation at $92^{\circ} \mathrm{C}, 1 \mathrm{~min}$ annealing at $60^{\circ} \mathrm{C}$, and 1.5 min extension at $72^{\circ} \mathrm{C}$ ) with the final cycle having a 5 min extension.

\section{Cloning and sequencing of the PCR product}

All enzymatic manipulations were performed according to Sambrook et al. (1989). The EcoRI-digested PCR-amplified fragment was separated on a $1.5 \%$ LMP-agarose gel, recovered using the Geneclean II kit (Bio 101 Inc.), and cloned into plasmid pBluescript II KS + (Stratagene). Plasmid DNA was sequenced in both directions by the dideoxynucleotide method of Sanger et al. (1977) using a T7-sequencing kit (Pharmacia).

\section{Construction of the tMTbCAT expression vector}

The 261-bp promoter fragment was released from the cloning vector (see above) with $E c o$ RI/HindIII, filled-in with Klenow fragment, and ligated into the BamHI site upstream of the CAT gene in the promoterless vector $\mathrm{pBL}$ CAT3 (Luckow and Schütz, 1987). The correct orientation was verified by sequencing and the resulting construct was termed ptMTb-CAT (Fig. 1).

\section{Transfection and CAT assays}

Plasmids. (1) ptMTb-CAT contains the 261-bp tMTb promoter in front of the CAT gene in pBL-CAT3 (see above); (2) pBL-CAT2 (Luckow and Schütz, 1987) contains the herpes simplex virus thymidine kinase promoter 
(Tk) upstream of the CAT gene fused to the SV40 polyadenylation sequence; (3) pBL-CAT3 (Luckow and Schütz, 1987) is a derivative of pBL-CAT2 in which the Tk promoter has been removed; (4) pTk-CAT2E (Altschmied et al., unpublished) contains the 72-bp repeats of the SV40 enhancer as a double insertion downstream of the CAT gene in pBL-CAT2; (5) phMTII -CAT $_{A}$ (Friedenreich and Schartl, 1990) contains the 835-bp HindIII/NcoI promoter sequence of the human metallothionein $\mathrm{II}_{\mathrm{A}}$ gene $\left(\mathrm{hMTII}_{\mathrm{A}}\right)$ in front of the CAT gene in pBL-CAT3; (6) pCMVTk-CAT (Altschmied et al., unpublished) contains the 700-bp AluI/AluI enhancer sequence of the human cytomegalovirus (CMV) upstream of the Tk promoter in pBL-CAT2.

Cell lines. (1) A2, Xiphophorus xiphidium embryonal epitheloid cell line (Kuhn et al., 1979); (2) PSM, Xiphophorus interspecific hybrid melanoma cell line (Wakamatsu et al., 1984); (3) EPC, carp epithelioma papulosum cell line (Fijan et al., 1983); (4) RTH-149, rainbow trout hepatoma cell line (Fryer et al., 1980); (5) HepG2, human hepatoblastoma cell line (Knowles et al., 1984). A2, PSM and EPC were cultured as described (Friedenreich and Schartl, 1990). HepG2 was cultured at $37^{\circ} \mathrm{C}$ under $5 \% \mathrm{CO}_{2}$ in DMEM supplemented with $10 \% \mathrm{FCS}$, penicillin $(100 \mathrm{U} / \mathrm{ml})$, streptomycin $(100 \mu \mathrm{g} / \mathrm{ml})$, $2 \mathrm{~m} M$ L-glutamine, $20 \mathrm{~m} M$ Hepes and $\mathrm{NaHCO}_{3}(7.6 \mathrm{~g} / \mathrm{l})$, while RTH was cultured at room temperature without $\mathrm{CO}_{2}$ in EMEM containing amphotericin B ( $3 \mu \mathrm{g} / \mathrm{ml}$; Fungizone; Sigma) and all supplements except $\mathrm{NaHCO}_{3}$.

Transfections and CAT assay. Cell transfections were carried out in triplicates and repeated twice by the $\mathrm{CaPO}_{4}$ coprecipitation method (Gorman et al., 1982 ) as described for fish cells (Friedenreich and Schartl, 1990). CAT assays were performed according to Friedenreich and Schartl (1990) and Gorman et al. (1982). The promoter activity was reflected by percent CAT conversion calculated by comparing the 3-acetylated (3-Ac) chloramphenicol $(\mathrm{Cm})$ and nonacetylated $\mathrm{Cm}$ as follows:

$\% \mathrm{CAT}$ conversion $=3-\mathrm{AcCm} /(3-\mathrm{AcCm}+\mathrm{Cm})$

In order to compare CAT activities between cell lines, relative percent CAT conversions were calculated by normalizing actual conversions against a positive, constitutively active plasmid (Table 1 ).

\section{Microinjection and in vivo transient expression}

Two-cell stage embryos of the Japanese medaka (Oryzias latipes) were used for microinjection. Transient functional CAT assay of the tMTb promoter was carried out as described elsewhere (Winkler et al., 1991, 1992). For the metal induction, embryos were treated with $\mathrm{ZnCl}_{2}$ (150 $\mu M$ final) for $24 \mathrm{~h}$ before sampling. 


\section{RESULTS}

\section{PCR cloning}

PCR is an in vitro method for enzymatic amplification of specific DNA sequences from minute quantities of DNA or RNA samples, using two oligonucleotide primers that hybridize to opposite strands and flank the region of interest in the target DNA. Repetitive cycles involving template denaturation, primer annealing, and extension of the annealed primers by heat-stable Taq DNA polymerase result in the exponential accumulation of a specific fragment whose termini are defined by the $5^{\prime}$ ends of the primers (Erlich, 1989). Based on the sequence available (Zafarullah et al., 1988) the expected PCR-amplified product would be $360 \mathrm{bp}$. The electrophoresis pattern of the

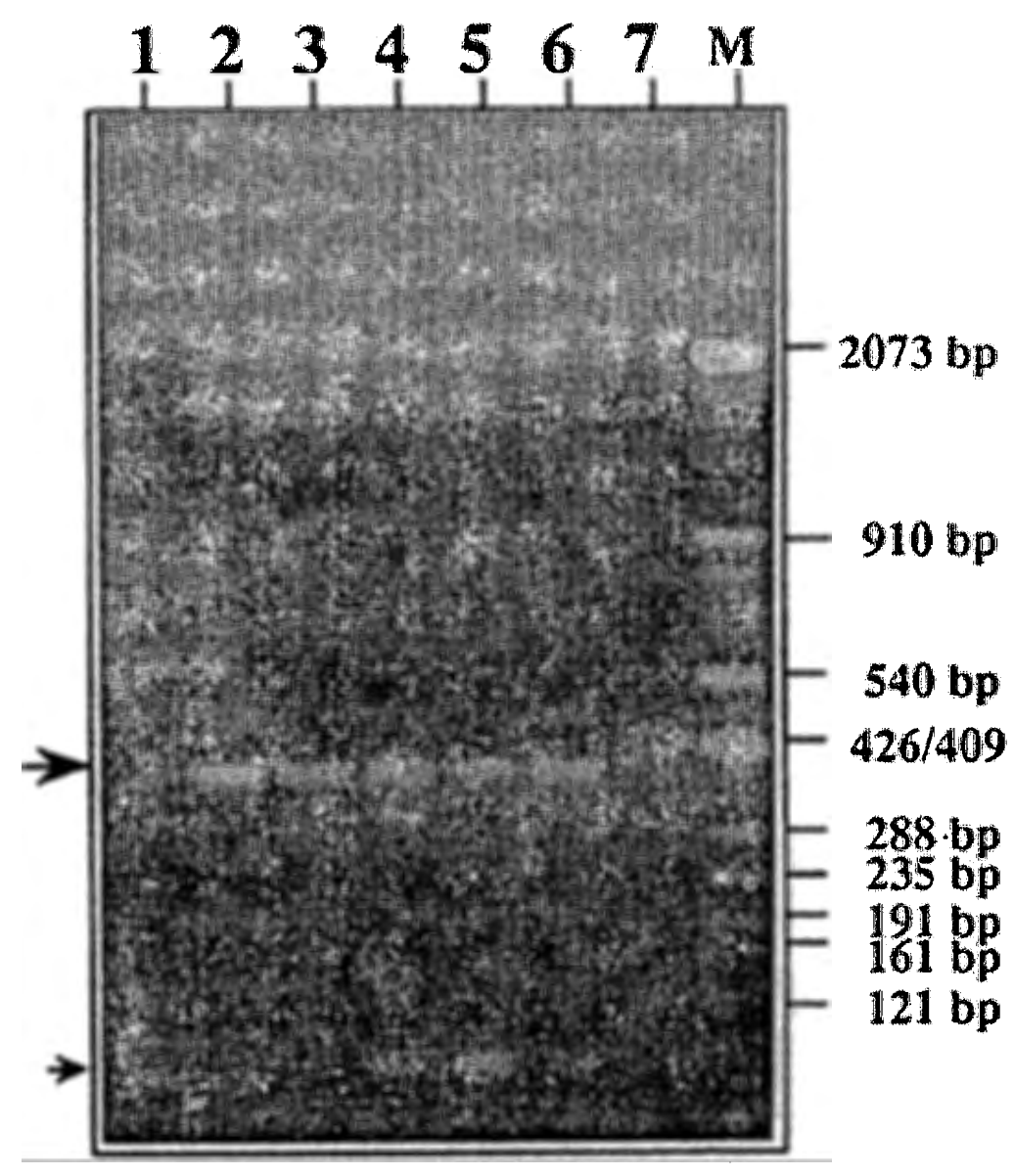

Fig. 2. Ethidium bromide stained $1.5 \%$ agarose gel showing a 360-bp PCR amplification product containing the promoter and first exon of the rainbow trout metallothionein $B$ gene. For each lane 10 $\mu l$ of the PCR reaction was loaded. Lanes 1-4: PCR reactions in Cetus buffer containing 50, 100, 150 and $200 \mathrm{ng}$ of the trout DNA and 2.5, 2.5, 1 and 1 unit of Taq polymerase, respectively. Lanes 5-7: PCR reactions in AM buffer using 50,100, and $0 \mathrm{ng}$ of the trout DNA and 1 unit of Taq polymerase. Marker (M) was pUC19 DNA digested with Ddel/EcoRI. The PCR product (big arrow) and the PCR primers (small arrow) are indicated. 
PCR product obtained was consistent with this prediction (Fig. 2). Identity of the amplified product was further confirmed by sequencing (see below).

\section{Sequencing of the cloned PCR-amplified fragment}

Sequence analysis revealed that the cloned PCR-amplified fragment is 363 bp in size, consisting of $352 \mathrm{bp}$ from the tMTb sequence and $11 \mathrm{bp}$ derived from the two PCR primers. The promoter region from the 5' end to the transcription start site (tsp; +1 ) is $62 \%$ AT-rich, contains a TATAAA signal and two copies of metal responsive element (MRE) consensus sequence which is thought to be responsible for the metal induction of MT genes. The tMTb sequence we obtained is essentially the same as that previously published (Zafarullah et al., 1988). However, differences at five positions have been found (marked by asterisks in Fig. 3). The seven bases 65-71 (Fig. 3) were absent in the genomic sequence published (Zafarullah et al., 1988). They were, however, present in the corresponding cDNA sequence (Bonham et al., 1987). Although we do not know if these discrepancies reflect a polymorphism present in different populations of rainbow trout, we believe that the sequence we obtained occurs naturally and that the differences are not due to errors of the Taq DNA polymerase.

\section{Transient expression in vitro of the CAT gene directed by the $t M T b$} promoter in fish and human cell lines

To study the metal-inducibility and cell type-specifity of the tMTb promoter we have used the CAT assay, where the bacterial CAT gene serves as a

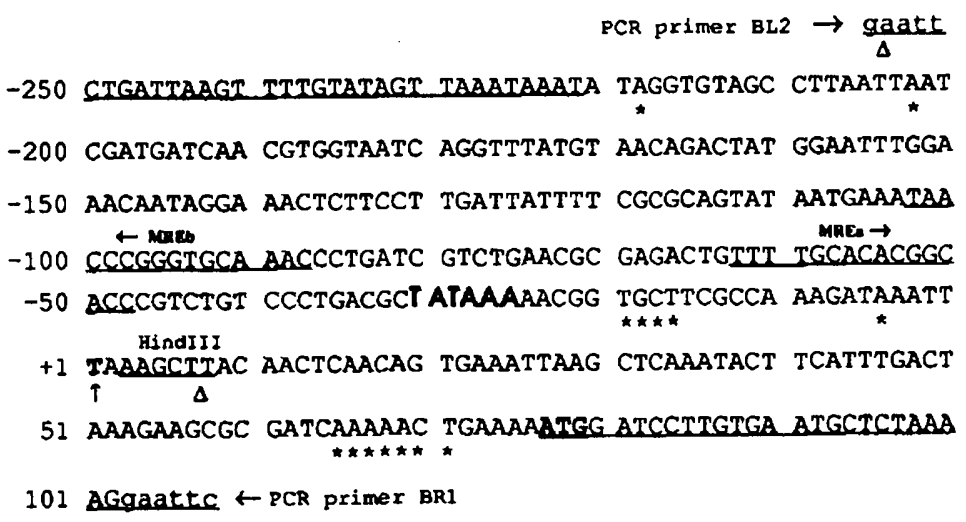

Fig. 3. Nucleotide sequence of the rainbow trout MTb promoter fragment cloned by PCR. Numbering begins with the transcription start point $(t s p ;+1)$ shown by a vertical arrow. The TATAAA box and the translation start codon ATG are bolded, the two putative MREs are underlined with arrows depicting their orientations relative to the tsp, and the HindIII site is indicated. The bases differing from that published previously are marked by asterisks. Open triangles define the promoter sequence cloned into the expression vector ptMTb-CAT. The PCR primers are underlined with arrows indicating their extension directions. The bases shown by lowercase letters at both ends were introduced by the PCR primers. 
TABLE 1

Activities of the promoters tested in one human and four fish cell lines ${ }^{\mathrm{a}}$

\begin{tabular}{|c|c|c|c|c|c|}
\hline \multirow[t]{2}{*}{ Constructs } & \multicolumn{5}{|l|}{ Cell lines } \\
\hline & HepG2 & RTH & EPC & $\mathrm{A} 2$ & PSM \\
\hline pBL-CAT3 & $0.13^{b}$ & 1.16 & 0.27 & 0.52 & 0.43 \\
\hline pBL-CAT2 & 1.00 & 3.14 & 3.67 & n.d. ${ }^{c}$ & n.d. ${ }^{c}$ \\
\hline pTk-CAT2E & 100.00 & 100.00 & 100.00 & 100.00 & 100.00 \\
\hline ptMTbCAT & 0.10 & i. 40 & 0.5 & 0.74 & 0.55 \\
\hline \multirow[t]{2}{*}{+ zinc } & 0.33 & 39.11 & 10.95 & 4.53 & 0.43 \\
\hline & (3.30) & $(27.94)$ & (21.9) & $(6.16)$ & (0) \\
\hline \multirow[t]{2}{*}{+ cadmium } & 0.11 & 7.18 & 1.02 & 11.62 & 0.40 \\
\hline & $(1.10)$ & $(5.13)$ & $(2.04)$ & $(15.80)$ & $(0)$ \\
\hline phMTII ${ }_{A}$ CAT & 1.21 & 14.11 & 3.68 & 3.71 & 0.96 \\
\hline \multirow[t]{2}{*}{+ zinc } & 72.56 & 480.69 & 139.00 & 99.28 & 13.26 \\
\hline & $(69.20)$ & (34.07) & $(37.77)$ & $(26.64)$ & $(13.84)$ \\
\hline + cadmium & $\begin{array}{c}13.90 \\
(11.50)\end{array}$ & $\begin{array}{l}227.48 \\
(16.12)\end{array}$ & $\begin{array}{l}106.67 \\
(29.00)\end{array}$ & $\begin{array}{c}98.12 \\
(26.33)\end{array}$ & $\begin{array}{c}5.66 \\
(5.91)\end{array}$ \\
\hline
\end{tabular}

${ }^{2}$ Cells were transfected with $3.5 \mathrm{p} M$ of plasmid DNA by the $\mathrm{CaPO}_{4}$ coprecipitation method. For metal induction the cells transfected with ptMTb-CAT and phMTII ${ }_{\mathrm{A}}$-CAT were treated with $\mathrm{ZnCl}_{2}(150$ $\mu M$ ) or $\mathrm{CdCl}_{2}(20 \mu M)$ for $48 \mathrm{~h}$ (fish cells) or $24 \mathrm{~h}$ (HepG2) before harvesting.

'The conversions were normalized to that of pTk-CAT2E whose actual conversion was defined as 100. The promoterless plasmid pBL-CAT3 was used as a negative control whose conversion was seen as background. Numbers in parentheses are induction fold, and were calculated by dividing the zinc/cadmium-induced conversion rate by the basal value (no metal treatment).

$c_{\text {n.d. }}=$ not determined.

reporter gene. Its expression can be easily monitored and the endogenous background CAT activity is negligible in fish (Friedenreich and Schartl, 1990).

As summarized in Table 1, the tMTb was active in all cell lines except in PSM, where it was completely inert even after metal treatments. The tMTb promoter exhibited an extremely low basal CAT expression which was barely above background. This is in contrast to the $\mathrm{hMTII}_{\mathrm{A}}$ promoter, which showed a higher basal level of CAT expression (2-12 fold higher than the tMTb promoter; Table 1 ).

Heavy metal induction of the tMTb promoter depended on the species origins of the cells and/or on the cell types. Among the four fish cell lines, the strongest metal-inducible activity was found in RTH, followed by EPC and A2, while in PSM this promoter was inactive (Table 1). These results, together with the fact that in vertebrates metallothioneins are mainly synthesized in liver, imply that the tMTb promoter drives expression of the metallothionein gene in a more cell type-specific manner. This is also in line with the in vivo expression pattern of the tMTb promoter in developing fish embryos, where it drives expression of the reporter gene in only a limited number of embryos. 
In order to see if the tMTb promoter also functions in mammalian cells, the human hepatoblastoma cells (HepG2) were used for transfection. Again, the metal-inducibility was observed. The activity of the tMTb was, however, much lower, leading to a maximal zinc-induced relative percent CAT conversion rate as low as 0.33 , compared to $11-39$ in homologous cell lines (except PSM). This means that the tMTb had activities up to 120 fold higher in fish cells than in human cells, indicating a strict fish cell-specific expression of the tMTb. This is supported by comparison of the highest metal-induced activities between the $\mathrm{hMTII}_{\mathrm{A}}$ and the tMTb. While in HepG2 the hMTII $\mathrm{A}$ promoter exhibited a zinc-induced (maximal) CAT expression 220 fold higher than that of tMTb, the levels decreased strongly in fish cells by a factor of 5 (RTH, zinc), 8 (A2, cadmium) and 13 (EPC, zinc) if compared to the tMTb, also demonstrating a higher activity of the tMTb promoter in fish cells than in human cells. Fish-specific expression of the fish MT promoter will become evident when a comparison is concentrated on RTH and HepG2, which both are of liver origin with the former being from fish and the latter from humans.

Both zinc and cadmium were found to be able to enhance considerably expression of the $\mathrm{tMTb}$-directed CAT gene, but their efficiencies were different depending on the cell line used. While in the trout hepatoma cells (RTH), carp epithelial cells (EPC) and human hepatoblastoma cells (HepG2) zinc was more efficient for induction, cadmium was superior in the Xiphophorus embryonal epithelial cells (A2), whereas in the Xiphophorus melanoma cells

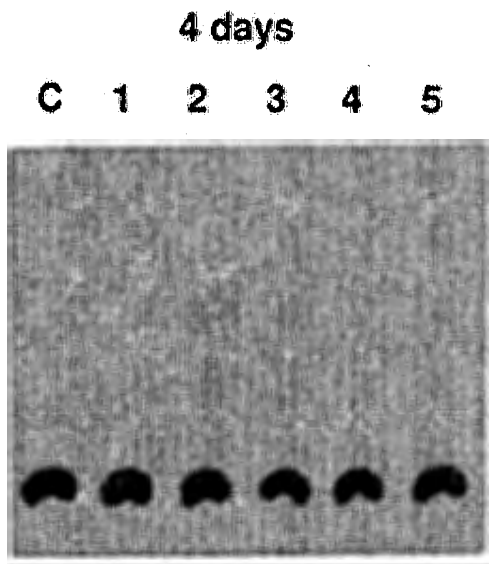

A. ptMTb-CAT
1 day

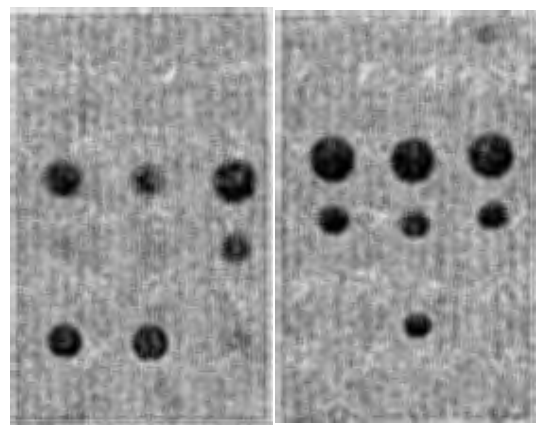

B. pCMVTK-CAT

Fig. 4. A representative in vivo CAT assay showing activity of the tMTb promoter in developing embryos of the medaka (Oryzias latipes). A: Samples 1-5 were prepared from embryos 4 days after injection with ptMTb-CAT. The embryos were treated with $\mathrm{ZnCl}_{2}$ (150 $\mu \mathrm{M}$ final) for $24 \mathrm{~h}$ before sampling. Sample C shows CAT expression in a non-injected, 2.5-day-old control embryo. B: Samples were prepared from embryos 1 day, 2 days and 3 days after injection with pCMVTk-CAT. Total protein extract from single embryos was used for each reaction. Acetylated forms of chloramphenicol are indicated by arrows. 
(PSM) both metals had no effect on the expression of the tMTb promoter (Table 1).

As compared to the tMTb, the hMTIIA was active and metal-inducible in all five cell lines, suggesting that its expression is less species-/cell type-specific.

Transient expression in vivo in fish embryos

To study the functionality and expression pattern of the tMTb promoter in vivo, we have conducted a transient expression assay by microinjection of the expression vector ptMTb-CAT into the cytoplasm of one cell of the 2-cell stage embryo of the Japanese medaka (Winkler et al., 1991). Our preliminary results show that this promoter is also functional in vivo (Fig. 4). In our experiments we found expression of the CAT gene only in a limited number of injected embryos ( 2 of 15 in $\mathrm{Zn}$-treated and 1 of 30 in untreated embryos), compared to an overall expression pattern obtained if a constitutively active, heterologous enhancer-promoter (CMVTk) is used to drive CAT expression. This can be explained by a non-ubiquituous activity of the tMTb promoter, that is restricted to specific tissues or developing organs, in combination with a strongly unequal distribution of injected DNA molecules, resulting in a highly mosaic expression pattern, as has been shown elsewhere (Winkler et al., 1991, 1992).

\section{DISCUSSION}

We have used the PCR technique to isolate the known tMTb promoter sequence. Because of its speed, specifity of amplification, and requirement of only minute amounts of DNA, PCR might find a wide range of applications in aquaculture in the near future. Of special interest is amplification of specific fragments for further functional analysis as in this study, or for direct sequencing, DNA typing, detection of viral and bacterial pathogens, and identification of novel genes in putative transgenics as an alternative to Southern analysis. PCR under certain conditions may also be useful to clone sequences from one species if the gene or promoter in question is known only from closely or distantly related species.

In our experiment the basal and metal-induced activity of the tMTb promoter was much lower than that of the $\mathrm{hMTII}_{\mathrm{A}}$ in all cell lines including RTH149 , in which the trout MTb promoter has previously been reported to be much stronger than its human counterpart (Zafarullah et al., 1988). In our construct ptMTb-CAT the promoter contains 261 bp of the $5^{\prime}$ end sequence (Fig. 3 ) of the tMT-B gene compared to $720 \mathrm{bp}$ in the construct ptMT-B CAT of Zafarullah et al. (1988). Whether this apparent difference in the promoter potencies is due to the additional upstream sequence in ptMT-B CAT and/or to the background plasmid sequences remains unknown.

It is interesting to note that the tMTb promoter was silent in the Xiphopho- 
rus melanoma cells (PSM), although some essential trans-acting protein factors might have remained in this cell line. This can be deduced from the metalinducibility of the human MTII $_{\mathrm{A}}$ promoter and of the trout MTa promoter, the promoter of the tMT-A, whose expression pattern was very similar to that of the tMTb except in PSM, where the tMTa was still zinc-/cadmium-inducible (unpublished data). This shows that for each kind of MT promoter, a cell type-specific regulation exists besides those features which determine more general characteristics of MT promoters, e.g., heavy metal-inducibility. In line with this finding are the results with the mouse MT enhancer and the X47, a MT-like promoter of Xiphophorus maculatus, which contains a consensus sequence of metal responsive elements (MREs) characteristic of MT promoters (Friedenreich and Schartl, 1990). Mouse MT enhancer has no effect on expression of a reporter gene in fish cells (see above). The X47 is constitutively active in EPC and A2 (Friedenreich and Schartl, 1990), whereas it is either silent in fish liver cells (RTH) or only slightly metal-inducible in human liver cells (HepG2) (Winkler et al., 1992). These data might indicate that the MREs themselves are not always sufficient for metal induction, and other still unidentified flanking sequences are also important for metal regulation of MT promoters.

To ensure effective expression of foreign genes in transgenic fish suitable promoters are required. All-fish constructs are preferable not only for correct expression of transgenes but also for marketability of transgenic aquaculture products. While reports on cloning of fish structural genes are rapidly increasing, studies on fish promoters are still at an early stage. This has led to the use of heterologous promoters in transgenic experiments in fish. However, in fish cell cultures the mouse MT-I enhancer fused to the Tk promoter was not able to enhance the expression of a reporter gene. Also the human $\mathrm{GH}$ gene controlled by the human MTII $_{\mathrm{A}}$ promoter did not produce any $\mathrm{GH}$ peptide at all (Friedenreich and Schartl, 1990). In the present study we have clearly shown that a fish promoter works much more efficiently in fish cells than in heterologous cells, pointing to the advantage of homologous sequences in transgenic experiments. This finding is intriguing in the light of reports that in most attempts to produce transgenic fish the heterologous promoters were not effective to drive the expression of the fused genes (see Chen and Powers, 1990). This indicates the general limitations for use of heterologous promoters in gene expression studies in vitro and/or in vivo and in the production of transgenic fish. In this study we have isolated and functionally tested the promoter of the rainbow MT-B gene to obtain information on its specificity. It was found that this promoter has a negligible basal expression, that it is metal-inducible, drives the expression of the reporter gene in a strict species- and cell type-specific manner, and that it is functional in vivo in developing embryos of the medaka. These properties make this promoter highly suitable both for the production of transgenic fish with known structural genes 
and for understanding the function of novel genes, as well as for in vivo studies on those genes whose expression may be lethal or detrimental (e.g., protooncogenes) to host organisms.

\section{ACKNOWLEDGEMENTS}

We thank Dr. R. Renkawitz, Martinsried, for kindly providing the plasmids pBL-CAT3, pBL-CAT2 and pTk-CAT2E, and H. Friedenreich, Martinsried, for the phMTII ${ }_{A}-C A T$. We are grateful to Dr. L. Gedamu, Calgary, Canada, for personal communications and for kindly providing the construct ptMT-B CAT. We also thank S. Romanov for typing the manuscript. This work was supported by grants to M.S. provided by G.I.F.(No.I-18-127.3/ 87 ) and the Bundesministerium für Forschung und Technologie through "Schwerpunkt: Grundlagen und Anwendungen der Gentechnologie" (No. 26). Y.H. is a fellow of the Deutsche Akademische Austauschdienst.

\section{REFERENCES}

Bonham, K., Zafarullah, M. and Gedamu, L., 1987. The rainbow trout metallothionein: molecular cloning and characterization of two distinct cDNA sequences. DNA, 6: 519-528.

Chen, T.T. and Powers, D.A., 1990. Transgenic fish. Trends Biotechnol., 8: 209-215.

Erlich, H.A. (Editor), 1989. PCR Technology: Principles and Applications for DNA Amplification. Stockton Press, New York.

Fijan, N., Sulimanoic, D., Bearzotti, M., Muzinic, D., Zwillenberg, L.O., Chilmonczyk, S., Vautherot, J.F. and De Kinkelin, P., 1983. Some properties of the Epithelioma Papulosum Cyprini (EPC) cell line from carp Cyprinus carpio. Ann. Virol. (Inst. Pasteur), 134E: 207220.

Friedenreich, H. and Schartl, M., 1990. Transient expression directed by homologous and heterologous promoter and enhancer sequences in fish cells. Nucl. Acids Res., 18: 3299-3305.

Fryer, J.L., McCain, B.B. and Leong, A.C., 1980. A cell line derived from rainbow trout (Salmo gairdnerii) hepatoma. Fish Pathol., 15: 193-200.

Gorman, C.M., Moffat, L.D. and Howard, B.H., 1982. Recombinant genomes which express chloramphenicol acetyltransferase in mammalian cells. Mol. Cell. Biol., 2: 1044-1051.

Knowles, B.B., Searles, D.B. and Aden, D.P., 1984. Human hepatoma-derived cell lines. In: F.V. Chisari (Editor), Advances in Hepatitis Research. Masson Publication Co. USA., Inc., Chicago, pp. 196-202.

Kuhn, C., Vielkind, U. and Anders, F., 1979. Cell cultures derived from embryos and melanoma of poeciliid fish. In Vitro, 15: 537-544.

Liu, Z., Moav, B., Faras, A.J., Guise, K.S., Kapuscinski, A.R. and Hackett, P.B., 1990. Functional analysis of elements affecting expression of the $\beta$-actin gene of carp. Mol. Cell. Biol., 10: 3432-3440.

Luckow, B. and Schütz, G., 1987. CAT constructs with multiple unique restriction sites for the functional analysis of eukaryotic promoters and regulatory elements. Nucl. Acids Res., 15 : 5490.

Palmiter, R.D., Brinster, R.L., Hammer, R.E., Trumbauer, M.E., Rosenfeld, M.G., Birnberg, N.C. and Evans, R.M., 1982. Dramatic growth of mice that develop from eggs microinjected with metallothonein-growth hormone fusion gene. Nature (London), 300: 611-615.

Sambrook, J., Fritsch, E.F. and Maniatis, T., 1989. Molecular Cloning: a Laboratory Manual, 2nd edn. Cold Springer Harbor Laboratory Press, NY. 
Sanger, F., Nicklen, S. and Coulson, A.R., 1977. DNA sequencing with chain-terminating inhibitors. Proc. Natl. Acad. Sci. USA, 74: 5463-5467.

Wakamatsu, Y., Oikawa, A., Obika, M., Hirobe, T. and Ozato, K., 1984. Fish hereditary melanoma cell lines of different degrees of cell differentiation. Dev. Growth Diff., 26: 503-513.

Winkler, C., Vielkind, J.R. and Schartl, M., 1991. Transient expression of foreign DNA during embryonic and larval development of the medaka fish (Oryzias latipes). Mol. Gen. Genet., 226: $129-140$

Winkler, C., Hong, Y., Wittbrodt, J. and Schartl, M., 1992. Analysis of heterologous and homologous promoters and enhancers in vitro and in vivo by gene transfer into Japanese medaka (Oryzias latipes) and Xiphophorus. Mol. Mar. Biol. Biotechnol., 1 (4/5): 326-337.

Wittbrodt, J. and Erhardt, W., 1989. An inexpensive and versatile computer-controlled PCR machine using a Peltier element as a thermoelectric heat pump. Trends Genet., 5: 202-203.

Zafarullah, M., Bonham, K. and Gedamu, L. 1988. Structure of the rainbow trout metallothionein B gene and characterization of its metal responsive region. Mol. Cell. Biol., 8: 44694476.

Zhu, Z., Li, G., He, L. and Chen, S., 1985. Novel gene transfer into the fertilized eggs of goldfish (Carassius auratus L. 1785). Z. Angew. Ichthyol., 1: 31-34. 